\title{
ENTREVISTA A JOSÉ DELGADO PINTO
}

\author{
Miguel Ángel Rodilla \\ Universidad de Salamanca
}

Miguel Angel Rodilla: Profesor Delgado Pinto, usted obtuvo la cátedra de Filosofía del Derecho, en la Universidad de Oviedo, en 1960, muy joven, con veintiocho años. Acaba de cumplir setenta años. Así que, incluso si dejamos fuera del cómputo sus años como profesor Ayudante y como profesor Adjunto en la Universidad de Granada, ha desarrollado una carrera académica muy dilatada. Estando ya cercana la jubilación, tal vez sea éste un momento oportuno para echar una mirada retrospectiva sobre su propia trayectoria y al mismo tiempo sobre los avatares de la filosofia del Derecho en España.

Para empezar, me gustaría preguntarle sobre su iniciación en la filosofía del Derecho. Usted empezó su carrera académica en el ámbito de la filosofía política y del Derecho constitucional, con una tesis sobre la formación del concepto de "leyes fundamentales". Muy pronto, sin embargo, cambió de rumbo, orientándose hacia la filosofía del Derecho. ¿Ese cambio de rumbo le resultó suave y natural, o supuso alguna ruptura? ¿Ha mantenido vivo el interés por la filosofía política?

José Delgado Pinto: Al terminar la Licenciatura comencé a trabajar en la elaboración de la tesis doctoral con Luís Sánchez Agesta, entonces catedrático de Derecho Político en la Universidad de Granada. En su Manual había una lección dedicada a "La constitución como Derecho fundamental de organización del Estado", y me sugirió que orientara mi trabajo en el sentido de aclarar ese carácter "fundamental" del subsistema jurídico que es una constitución. El trabajo fue derivando hasta terminar siendo un estudio sobre la formación histórica de la noción moderna de constitución. En un primer capítulo estudiaba la idea bajomedieval y renacentista de las "leyes fundamentales", para ir viendo cómo progresivamente se transformaba y era finalmente sustituida por la idea moderna de constitución. Dediqué sendos capítulos a examinar ese proceso en el período de la revolución inglesa en la época de Cromwell, la aportación del yusnaturalismo racionalista de los 
siglos XVII y XVIII, la evolución en Norteamérica desde el período de las colonias hasta la independencia frente a Inglaterra, y, finalmente, el momento de la revolución francesa. Tuve ocasión entonces de leer, de forma parcial en unos casos, más completa en otros, algunas de las obras de una serie de "clásicos" de la filosofía jurídico-política: Bodino, Suárez, Grocio, Hobbes, Locke, Pufendorf, de Vattel, Rousseau, entre otros.

Defendí mi tesis doctoral en enero de 1957. En mayo o junio de ese mismo año se incorporó Agustín de Asís a la cátedra de Derecho Natural y Filosofía del Derecho de Granada, que llevaba bastantes años vacante. Agustín de Asís consiguió que se creara una plaza de Profesor Adjunto de Derecho Natural y Filosofía del Derecho. (En aquellos tiempos para ser profesor adjunto había que ser doctor y superar los ejercicios de una oposición que se celebraba en la misma Facultad. El nombramiento era por cuatro años, tras los cuales, para continuar, había que superar un nuevo concurso-oposición). Como la Adjuntía de Derecho Político estaba ocupada, el profesor Sánchez Agesta, estando de acuerdo Agustin de Asís, me aconsejó que preparase los ejercicios correspondientes a la Adjuntía de Derecho Natural y Filosofía del Derecho, cosa que hice. La oposición tuvo lugar en la primavera de 1958 y fui nombrado Prof. Adjunto. De esta manera pasé de Derecho Político a Filosofía del Derecho. Como el tiempo que dediqué a la primera disciplina -fundamentalmente a preparar la tesis doctoral- no fue muy dilatado, y dado el modo como enfoqué el tema de la tesis, el paso a la Filosofía jurídica no representó en absoluto un cambio brusco. Cuanto leí y estudié mientras estuve adscrito a Derecho Político me fue de gran utilidad ya en aquella época y posteriormente. Me procuró la gran ventaja que supone estar familiarizado con la historia del pensamiento filosófico-político, habiendo profundizado en unos siglos en los que, además, la filosofía política formaba unidad con la filosofía moral y la filosofía del Derecho.

Siendo ya profesor adjunto conseguí una beca del Ministerio de Educación que me permitió continuar mis estudios en la Universidad de Munich durante el curso 1958-59. A mi vuelta a Granada en el verano de 1959 se habían convocado oposiciones para cubrir las cátedras vacantes de nuestra disciplina en las Universidades de Murcia y Oviedo. Los ejercicios se prolongaron varios meses -entonces eran seis ejercicios, participamos bastantes opositores y hubo alguna interrupción- y terminaron en abril de 1960. Mariano Hurtado obtuvo la primera cátedra, y ocupó la vacante de Murcia. Yo fui propuesto para la segunda, y pasé a hacerme cargo de la de Oviedo, donde permanecí durante el curso 1960-61. A comienzos del curso siguiente, en virtud de concurso de traslado, me incorporé a la Universidad de Salamanca. 
Dice usted que obtuve la cátedra muy joven. Y es verdad. Con todo, el mío no fue un caso extraordinario en aquella época. Si se consultan los datos pertinentes, se puede comprobar que en nuestra disciplina (entonces existían, si no me equivoco, catorce cátedras) fueron varios los que llegaron a la cátedra con una edad similar a la mía, e incluso uno o dos siendo más jóvenes. Obtener la cátedra tan joven representó en general una ventaja. Pero desde un punto de vista fue también un inconveniente. Pues supuso que hube de hacerme cargo inmediatamente, sin ayuda efectiva durante varios años, de la docencia en primero y quinto cursos y de otra serie de tareas como la formación de una biblioteca de la disciplina, que no existía en absoluto, la dirección de las primeras tesis doctorales, etc. Se echaba mucho de menos entonces la existencia de una figura como la de los actuales Profesores Titulares.

M.A.R.: En su reciente contribución al libro publicado en homenaje a Luis García San Miguel usted se ha situado a si mismo dentro de una primera generación de filósofos del Derecho que hicieron sus estudios después de la guerra civil. No hay duda de que la guerra y las condiciones politicas e intelectuales del regimen franquista introdujeron una cesura en el desarrollo normal de la filosofía del Derecho en España. ¿Cómo ve usted la relación de su propia generación con la generación anterior?

J.D.P.: Lo esencial de lo que yo puedo decir sobre este asunto ya lo he dicho en el estudio publicado en el homenaje a Luis García San Miguel. Lo que puedo añadir ahora no pasará de glosa de lo escrito allí.

Creo que al hablar de este tema se corre el riesgo de incurrir en simplificaciones. En ciertas circunstacias o contextos es necesario y útil simplificar. Pero, siempre que se pueda, la simplificación debe ser completada con un análisis más detallado que permita una visión más amplia y más matizada de la época. Se ha repetido muchas veces que, en cuanto a nuestra disciplina, la época del régimen franquista supuso la imposición de un yusnaturalismo de corte tradicional, aislado de las corrientes filosófico-jurídicas contemporáneas; y que sólo a partir de la mitad de los años sesenta, por obra de algunos profesores de una nueva generación de filósofos del Derecho, se inició la crítica al yusnaturalismo imperante y la apertura a las tendencias contemporáneas, la normalización de la disciplina en suma. Esto es cierto; pero representa una simplificación, y debe ser matizado situándolo dentro de una visión más completa de ese período.

Para empezar, los que ocupaban las cátedras de filosofía del Derecho en los primeros tiempos del régimen de Franco no pertenecen a una generación, sino a varias. Aún utilizando el concepto de generación de forma flexible, habría que distinguir al menos dos generaciones: la de quienes ya eran catedráticos antes del inicio de la guerra civil y la de los que obtuvieron la cáte- 
dra en los años de la inmediata postguerra. Y dentro de cada grupo hay que seguir distinguiendo, pues no todos fueron defensores de un yusnaturalismo de corte tradicional. Así, refiriéndonos al primer grupo, ni Luis Recaséns, ni Luis Legaz, ni Felipe González Vicén, entre otros, profesaron ese yusnaturalismo; su formación y sus publicaciones muestran que estaban al día respecto de las tendencias filosófico-jurídicas contemporáneas, y que podrían haber impulsado un desarrollo de la disciplina acorde con el despliegue de dichas tendencias. En cuanto a los integrantes del segundo grupo, tampoco eran todos yusnaturalistas; dentro de los que lo eran se pueden distinguir orientaciones diversas; además, casi todos ellos conocían bien las corrientes filosófico-jurídicas contemporáneas como se puede comprobar consultando sus tesis doctorales y otras publicaciones monográficas. De forma que un examen de lo publicado en nuestro campo durante las décadas de los años cuarenta y cincuenta muestra que no todo fue, ni mucho menos, manifestación de un yusnaturalismo de corte tradicional.

Sin embargo, es cierto que ésa fue la tendencia dominante. Este dominio fue abrumador en el ámbito de la docencia, en los cursos que se impartían y en los manuales que se utilizaban. También lo fue en lo que se refiere a la formación de nuevos profesores, ya que la aceptación del yusnaturalismo se convirtió en algo así como un requisito necesario para el acceso a las cátedras. Esta situación de dominio fue consecuencia de la guerra y de la ideología que el bando dominante impuso en la postguerra, impidiendo lo que de otro modo hubiera sido el desarrollo normal de la disciplina.

Estas afirmaciones genéricas se pueden ejemplificar y completar reparando, aunque sea muy brevemente, en la trayectoria de algunos de los catedráticos de la asignatura. De los integrantes de la primera generación que mencioné más arriba, diciendo que hubieran podido impulsar un desarrollo diferente de la filosofía del Derecho en nuestro pais, Recaséns se exilió, aunque no fue el único. Es verdad que desde 1964, aproximadamente, volvió regularmente por España y estableció algunas relaciones institucionales con la Universidad española; pero en las décadas anteriores, aunque sus escritos eran conocidos, no participó en la docencia ni en la formación de discípulos. González Vicén fue privado de su cátedra en plena guerra; en 1946 fue repuesto en la cátedra, ocupando la de La Laguna, donde permaneció ya hasta su jubilación. Su docencia allí y sus publicaciones se orientaron en una línea diferente de la dominante; pero por razones comprensibles durante bastantes años se mantuvo al margen de una serie de actividades, como la formación de discípulos y otras, a través de las cuales podía haber tenido una mayor influencia en la orientación de la disciplina. Legaz colaboró con el bando victorioso, y en algunas publicaciones trató de apuntalar doctrinalmente el nacionalsindicalismo; después evolucionó y mantuvo una posición más 
independiente. Su Introducción a la Ciencia del Derecho de 1943 se apartaba claramente de los manuales yusnaturalistas al uso; y en sus sucesivas reediciones y reformas mostraba la perfecta información que poseía su autor de las novedades filosófico-jurídicas en todo el mundo. Varios profesores iniciaron su formación bajo su patrocinio; pero por diversas razones, en gran medida por su propio carácter, no ejerció en la marcha de la asignatura la influencia que hubiera cabido esperar.

De los siete profesores que obtuvieron la cátedra entre 1940 y 1945 , aquellos que por su formación y sus convicciones podían haber orientado la filosofía del Derecho en una dirección diferente a la del yusnaturalismo neoescolástico que se estaba imponiendo (pienso, por ejemplo, en Gómez Arboleya, Lissarrague, Truyol) poco pudieron hacer en los primeros tiempos de la postguerra, dada la presión político-ideológica de entonces. Después, a partir de la segunda mitad de los cincuenta, sí que podrían haber iniciado un cierto giro en la disciplina, como el que tuvo lugar en otras. Pero entonces ocurrió que, por distintos motivos, la abandonaron. Éste fue, a mi entender, un hecho decisivo para la evolución de la filosofía del derecho en España durante los años siguientes, porque, unido a los antes aludidos, supuso que el protagonismo quedó en manos de los partidarios del mantenimiento a ultranza del statu quo. Todo ello explica que el cambio de rumbo en la filosofía del Derecho fuera una tarea que terminara recayendo en esa generación que ya hizo sus estudios en la Universidad de la postguerra.

M.A.R.: Permitame que le pida que complete un poco más estas consideraciones. ¿Tendría inconveniente en hacer una breve semblanza de algunos de los profesores pertenecientes a la generación anterior con los que, por unas razones $u$ otras, usted tuvo mayor relación? No ignoro que puede ser delicado. Pero tal vez tenga interés para los más jóvenes, y para la pequeña historia de nuestra comunidad académica.

J.D.P.: Intentémoslo. Pero en todo caso no espere una semblanza propiamente dicha, que requeriría más espacio y más datos de los que ahora dispongo. Lo que puedo intentar hacer, apoyándome en los recuerdos que conservo, es enhebrar algunas impresiones sueltas que seguramente tendrán una utilidad muy relativa, pues son naturalmente subjetivas, y no pueden pretender ninguna otra clase de validez. Pero ¿de quién quiere que hablemos?

M.A.R.: Empecemos, si le parece, por el profesor González Vicén.

J.D.P.: A Felipe González Vicén lo conocí personalmente en febrero de 1963 en La Laguna cuando, aceptando su invitación, formé parte del tribunal que juzgó la tesis doctoral de su hijo Juan Luis, que versaba sobre la filosofía jurídica y política de Justus Möser. En esa ocasión, y también a invitación suya, pronuncié una conferencia en la Facultad de Derecho en la 
que hablé sobre "Derecho natural e historia", un tema sobre el que trabajaba entonces. Como era de esperar, en las conversaciones que mantuvimos durante los varios dias que permanecí en la Laguna quedó bastante claro su rotundo rechazo del yusnaturalismo y, en concreto, de los intentos de cohonestar sus postulados con la aceptación de la historicidad del Derecho - aunque la cortesía le llevó a acrecentar las alabanzas y velar o suavizar las críticas.

Volví a tratar a D. Felipe en bastantes ocasiones más, tanto en la La Laguna como en Madrid. La vez en que la relación personal fue más prolongada tuvo lugar cuando ambos formamos parte del tribunal de aquellas accidentadas oposiciones que culminaron en 1974 con la propuesta de Gil Cremades y Elías Díaz para las cátedras de Zaragoza y Oviedo. En el primer ejercicio el tribunal (en el que yo me integré a última hora, como el último suplente disponible) estaba compuesto por los cinco miembros reglamentarios. Pero al final solo quedamos tres: D. Felipe, Nicolás López Calera y yo. Entretanto, durante un par de años, hubo interrupciones, provocadas, primero, por un recurso interpuesto por el profesor Elías de Tejada y, después, por el abandono del tribunal por parte del presidente. Y hubo presiones de todo tipo para impedir el desenlace que finalmente se produjo. La tranquilidad y el ánimo de D. Felipe fueron decisivos en aquel trance, aunque también es cierto que desde el principio su posición era la más sólida, la menos vulnerable, y que, por tanto, las presiones más fuertes se ejercieron sobre los flancos más débiles, que éramos Nicolás López Calera y yo.

La primera impresión que producía González Vicén era la de una persona distante, cortés pero distante. Sin embargo, si el trato se prolongaba, esa impresión se desvanecía y uno se encontraba con un hombre afable, buen conversador, que de cuando en cuando hacía uso de un humor irónico, y que en algunas ocasiones se revelaba como un gran fabulador de peripecias personales. Sin embargo, creo que respecto de sus compañeros de cátedra sí que mantuvo una actitud conscientemente distante. Tengo la impresión de que quiso mantenerse aparte. De hecho se encontró siempre más a gusto, más participativo, con los integrantes de las nuevas generaciones de filósofos del Derecho.

También por su pensamiento filosófico-jurídico, por su obra, González Vicén representa un hito singular en el panorama de la filosofía jurídica española de entonces. No sólo por su antiyusnaturalismo, que también, sino además por la temática que cultivó y por la posición doctrinal que mantuvo. Era fácil percibir algunos rasgos que destacaban en su personalidad como filósofo del Derecho: el rechazo sin compromisos del yusnaturalismo, la atracción que sentía por el pensamiento historicista y la facilidad y fluidez 
con que manejaba en sus fuentes originales el pensamiento de los siglos XVIII y XIX, sobre todo el alemán.

Su obra escrita no es muy extensa, pero sí de gran calidad, extremadamente cuidada y sólidamente documentada. En su mayor parte es de carácter historiográfico: aparte de su estudio sobre Kant, se ocupó sobre todo del paso histórico del yusnaturalismo al positivismo y de una serie de tendencias y autores encuadrables dentro de la gran corriente positivista. Son muy pocos los escritos en que expresa su propio pensamiento, aunque éste va quedando expuesto aquí y allá en sus publicaciones de naturaleza historiográfica. La suya es una concepción positivista, si llamamos positivista a toda posición antiyusnaturalista. Pero se trata de un positivismo difícilmente encasillable en alguna de las corrientes más conocidas, ya que el rasgo más destacado de su manera de entender el Derecho es el historicismo.

De todos modos me gustaría añadir que el historicismo de González Vicén adquiere en ocasiones perfiles que parecen contrapuestos. Unas veces resulta compatible con un individualismo liberal que coloca por encima de todo la persona individual y su conciencia. Esto se aprecia, además de otros trabajos suyos, en su conocido estudio de 1979 sobre la obediencia al Derecho en el que, como es sabido, afirma que mientras que no hay un fundamento moral para la obediencia al Derecho, sí hay un fundamento ético absoluto para la desobediencia. En otras ocasiones, sin embargo, parece profesar un historicismo idealista conforme al cual en el Derecho de cada época se manifestaría una racionalidad y un "ethos" más valiosos que los variables intereses y fines de los individuos. Se ha dicho a veces que esta forma de pensar correspondería a una primera etapa en la evolución de su pensamiento. Pero yo creo que está también presente en su pensamiento último. En este sentido puedo referirme a uno de sus últimos manuscritos: unos pocos folios mecanografiados que envió a los organizadores de las X Jornadas de Filosofía Jurídica y Social que se celebraron en Alicante en diciembre de 1987 para que se leyeran en el homenaje que se le iba a tributar en ese marco. En ese curioso documento de autointerpretación confiesa: "Desde un principio, hace ya años, se me hizo difícil asentir a esta "utopia liberal", que veía en el Derecho sólo la organización de la fuerza y el asentamiento de los pilares de la convivencia. Para mí el Derecho era algo más que la organización o la satisfación de finalidades humanas contingentes; es una fuerza histórica que los hombres manejan, como manejan otras, sirviendo así para cumplir el fin de la humanidad, más allá de toda teología o moralidad al uso". Creo que sería muy pertinente que se realizara un estudio amplio, una tesis doctoral tal vez, en el que se aclarara este y otros aspectos del pensamiento filosófico-jurídico de González Vicén. 
En todo caso, no cabe duda de la fecundidad de su obra. De hecho ha dado lugar a dos de las más amplias polémicas doctrinales que se han registrado en el ámbito de la reciente filosofía práctica en España. La primera se originó con la publicación en 1969 de su trabajo sobre "La filosofía del Derecho como concepto histórico": su tesis de que la filosofía del Derecho es un modo de saber que sólo surge con el declinar del yusnaturalismo se ha discutido y sigue discutiéndose en numerosas publicaciones, y también en muchísimas "Memorias " de cátedra y "Proyectos docentes". La segunda polémica, más llamativa y más reciente, es la que provocó su estudio de 1979, antes aludido, sobre la obligación moral de obediencia al Derecho, que ha producido ya una literatura bastante considerable, sobre la que incluso existe alguna tesis doctoral.

M.A.R.: ¿Y el profesor Legaz? ¿Cuál fue su relación con él? Ocupó durante muchos años la Presidencia de nuestra Sociedad, pero ¿qué papel cree usted que desempeñó en la filosofía del derecho española?

J.D.P.: A Luis Legaz lo conocí en las sesiones del congreso sobre "Derecho y Paz" que se celebró en Madrid, en octubre de 1964, organizado por la Sociedad Española de Filosofía Jurídica y Social que él presidía. Después, gracias a su intervención, el Instituto de Estudios Europeos A. Rosmini me invitó a participar en unas jornadas en Bolzano en noviembre de 1968, que versaron sobre el tema "Historicidad o relativismo: alternativa de la conciencia europea", aunque el propio Legaz finalmente no pudo asistir. Volví a encontrarme con él en Bruselas en 1971 en el congreso sobre "El razonamiento jurídico", organizado por la Asociación Internacional de Filosofía Jurídica y Social (IVR). Nuestra relación personal fue más prolongada e intensa con motivo también de otro congreso patrocinado por la IVR, que se celebró en Madrid en 1973. Estaba previsto que los congresistas dedicaran un día a visitar la Universidad y la ciudad de Salamanca, y eso requirió una serie de gestiones que realicé conjuntamente con él.

He dicho lo que antecede para destacar un aspecto de su personalidad que tiene para mí un claro valor sintomático: Legaz fue un asiduo participante en los congresos y jornadas nacionales e internacionales de nuestra disciplina y de disciplinas afines. Pero esto, como digo, es sólo una manifestación parcial de la forma como, en general, asumió la tarea de profesor de filosofía del Derecho. Puede decirse que de todos sus colegas fue el que de forma más intensa y participativa se dedicó a profesar nuestra disciplina. Si me permite expresarlo así, fue el más "profesional" de todos los de su generación.

Hay que recordar que fue Presidente de la Sociedad Española de Filosofía Jurídica y Social desde su fundación en 1963 hasta su muerte; pues fue ya después de ésta, en 1982 si no me equivoco, cuando se eligió como 
nuevo Presidente a Agustín de Asís. También fue miembro del Präsidium de la IVR. Y, después de unos primeros años en que lo dirigió Enrique Gómez Arboleya, fué Director del Anuario de Filosofía del Derecho hasta que dejó de publicarse en 1977. El desempeño de estos cargos, entre otras razones, le exigió y le permitió conocer y mantener un contacto permanente con los más destacados filósofos del Derecho de diversos paises: Italia, Austria y Alemania, Bélgica... Por eso, y por su dedicación continua, Legaz siempre se mantuvo al corriente de las últimas novedades bibliográficas y movimientos doctrinales en nuestra disciplina. Eso hacía que no supusiese para él un gran esfuerzo participar en reuniones y congresos, o en publicaciones colectivas, con conferencias, ponencias o artículos sobre muy diversos temas. En otra ocasión ya he llamado la atención sobre el hecho de que en 1975, cuando en el número 15 de los Anales de la Cátedra Francisco Suárez gran parte de los profesores españoles de filosofía del Derecho expusieron su punto de vista sobre el sentido y la temática de la disciplina, de los catedráticos de antes de la guerra y de los que lo fueron en la inmediata postguerra sólo él y Luis Recaséns aportaron su colaboración.

Estos rasgos de su personalidad como profesor se manifiestan también en su obra escrita, que es muy amplia: quizá una docena de libros y bastantes más del centenar de artículos de revista o contribuciones similares. Llama la atención un dato: que la mayoría de los trabajos se centran en la temática contemporánea de la filosofía del Derecho; aunque bastantes son de naturaleza historiográfica, o inciden en disciplinas afines, son muchos más los que versan sobre diversas cuestiones filosófico-jurídicas, tratadas siempre con profundidad y con una amplia información de la actualidad doctrinal. Esto último se pone de manifiesto llamativamente en su obra más importante, su Filosofía del Derecho, que inicialmente se publicó en 1943 con el título de Introducción a la Ciencia del Derecho, y que tuvo numerosas reediciones y revisiones. Esa obra se presenta como un libro para la enseñanza, pero supera ampliamente los límites de un manual para alumnos universitarios; en realidad se trata de un amplio tratado sistemático de nuestra disciplina. No soy el primero en destacar la singularidad de esta obra en el panorama de la filosofía jurídica española de su época; creo que sólo le es parangonable el Tratado de Recaséns, algo posterior, que carece, sin embargo, de la información y el apoyo bibliográfico de la obra de Legaz. Hay dos rasgos que me parece que caracterizan bien esta obra: en primer lugar, lo que podemos llamar su voluntad de sistema, de tratar todos los temas más importantes de la filosofía del Derecho y de hacerlo siguiendo un orden comprensible; en segundo lugar, la amplísima información en que se basa, pues respecto de cualquier cuestión se cita y se valora un altísimo número de aportaciones doctrinales, incluidas las más recientes. 
Algunas veces me he preguntado por las razones que pueden explicar que Legaz no haya dejado una huella mayor en nuestra filosofía jurídica contemporánea: que no haya más trabajos que estudien su pensamiento, que no haya tenido más discípulos etc.. Conozco la tesis doctoral de Jesús Primitivo Rodríguez sobre su filosofía política, y algunos otros trabajos menores; pero en la obra de Legaz hay materia para varios estudios de envergadura. Buena parte de la explicación puede que se encuentre en nuestra tendencia a no considerar digno de estudio y de debate el pensamiento de nuestros compatriotas. Pero, además de ésta, creo que pueden apuntarse otras razones explicativas. Para empezar, tal vez su misma posición política: inicialmente Luis Legaz colaboró doctrinalmente con el regimen franquista, después adoptó una línea más independiente, quedando por último en una posición que no estaba decididamente ni con unos ni con otros. También ha podido influir el carácter de su obra, de su pensamiento, en ocasiones marcadamente sincrético; su mismo afán de dar cuenta y de tener en cuenta los más diversos autores y corrientes doctrinales fué, tal vez, un obstáculo para articular de forma más enérgica una doctrina propia en la que destacaran unas tesis claras y relativamente originales. En cuanto a los discípulos fueron bastantes, o muchos, los que iniciaron sus estudios de filosofía del Derecho con él, o elaboraron su tesis doctoral bajo su dirección; pero el carácter de Legaz, afable, pero tímido y más bien retraído, no era el más adecuado para participar decididamente en la pugna, a veces dura y no demasiado escrupulosa, por la asignación de las plazas académicas.

M.A.R.: Terminemos, si le parece bien, con Francisco Elías de Tejada, una figura muy controvertida, que durante años jugó un papel muy destacado - y yo creo que bastante perturbador - en la vida institucional de nuestra pequeña comunidad, y con quien usted tuvo relaciones particularmente dificiles.

J.D.P.: Bastantes profesores de filosofía del Derecho de mi generación y muchos más de las siguientes consideran al Prof. Elías de Tejada como a quien durante años dispuso a su antojo de las cátedras de la disciplina, atribuyéndolas a sus discípulos y amigos, y negándolas a los demás, sobre todo si no defendían el yusnaturalismo tradicional, y dominando de este modo la filosofía jurídica española hasta el final del franquismo. Esta imagen contiene un núcleo de verdad; y es comprensible que sea la que se ha transmitido entre los integrantes del gremio filosófico-jurídico. Pero creo que debe ser matizada y completada.

A Elías de Tejada lo traté más, y más intensamente, que a los demás catedráticos de su generación, por lo que puedo hablar de los muy peculiares rasgos de su personalidad, aunque al hacerlo no sea original, pues ya otros se han referido a los mismos, en particular Miguel Ayuso en la tesis docto- 
ral que dedicó a su obra (en la que ignora, por cierto, la faceta a la que he empezado refiriéndome). Así, es verdad que fué un políglota excepcional: dominaba muchos idiomas, entre ellos, por supuesto, todos los requeridos para comprender y estudiar sin intermediarios las distintas tradiciones filosófico-jurídicas. También fue un viajero infatigable. Y como estaba dotado de una gran curiosidad intelectual y de mucho más que suficientes recursos económicos, fue formando una biblioteca que llegó a ser asombrosa, mucho mejor dotada que la de cualquiera de los departamentos universitarios que yo conocía. Además recordaba perfectamente la situación de cualquier libro o folleto en su biblioteca, y siempre estaba dispuesto a facilitarle a uno su manejo. Pues una cualidad que le distinguía era la generosidad, incluída la generosidad en cuanto al tiempo que estaba dispuesto a dedicar a los demás. Era hombre de una extraordinaria vitalidad y de una capacidad de trabajo pasmosa, extrovertido y gran conversador. También era radical en las ideas y extremadamente tenaz y combativo, de una combatividad únicamente paliada por su completa falta de doblez.

$\mathrm{Su}$ obra escrita es ingente ya por su cuantía, pues comprende varios cientos de contribuciones entre libros, artículos y folletos. Su temática, además, es muy dispar como revela el mero enunciado de algunos títulos que me vienen ahora a la memoria: desde estudios de carácter sistemático, como la Introducción al estudio de la ontología jurídica, a investigaciones histórico-filosóficas de temática tan variada como El hegelismo jurídico español, Las doctrinas políticas de la Baja Edad Media inglesa y La filosofía del Derecho y del Estado en Rumanía, hasta estudios historiográficos de la envergadura de los cuatro volúmenes sobre el Nápoles Hispánico. En muchísimos casos se trata de trabajos en los que se pone de manifiesto una gran erudición, apoyada en un ingente caudal de lecturas. Es asombroso que un hombre que viajó tanto, y que emprendió tantas otras actividades, dispusiese aún de tiempo para procurarse una información tan amplísima y variada. Lamentablemente no se encuentra en sus escritos un desarrollo sistemático, suficientemente completo y articulado, y relativamente original de la temática iusfilosófica.

Estas características de su obra se ven muy bien reflejadas en su trabajo más importante en nuestro campo, el Tratado de Filosofía del Derecho, del que sólo llegaron a publicarse los dos primeros volúmenes en 1974 y 1977. Se trata de una obra verdaderamente sorprendente. Son dos grandes libros que suman unas mil doscientas páginas de apretada tipografía, que contienen sólo cinco breves lecciones en las que su autor, de forma clara y didáctica, expone cuáles son a su juicio los distintos tipos del saber jurídico en el marco del saber humano en general y sus modalidades. Sin embargo, la casi totalidad del espacio lo ocupan setenta y tantas glosas que vienen a ser otros 
tantos capítulos de una historia de las relaciones entre ciencia y filosofía y de la configuración del saber jurídico. Muchas de estas glosas constituyen excelentes estudios monográficos sobre determinados autores o épocas en relación con la temática señalada. Es sorpredente el contraste entre las sucintas lecciones y el ingente alarde historiográfico que constituyen las glosas. Y es que lo verdaderamente valioso de la aportación del Prof. Elías de Tejada es su obra historiográfica, sus numerosos estudios de historia de las ideas jurídicas y políticas. En lo que se refiere al sistema de filosofía del Derecho, se declaró siempre defensor del yusnaturalismo de santo Tomás, tal como fué desarrollado por los juristas de nuestro siglo de oro, frente al yusnaturalismo moderno de raíz protestante y frente al positivismo. En el plano de la filosofía política profesó con toda decisión el tradicionalismo, lo que no deja de ser llamativo en plena mitad del siglo XX en un filósofo del Derecho tan bien informado como él.

Hacia mediados de los años sesenta Elías de Tejada volcó muchas de sus energías en las oposiciones que se celebraban para dotar las cátedras vacantes, y durante una década aproximadamente hizo cuanto pudo para dominar las decisiones de los correspondientes tribunales. Creo que es importante la cuestión de la época. A mi modo de ver antes de la fecha señalada Elías de Tejada, que siempre fué muy activo organizando conferencias, congresos, iniciativas editoriales, etc. para la difusión de sus ideas, no manifestó mayor interés, ni realmente tuvo mayor influencia en la cuestión de las cátedras que la que tuvieron otros catedráticos de la disciplina. Cuando se propuso controlar el desarrollo de las oposiciones fué en una época tardía en la evolución del regimen franquista, en la que ya se había producido una cierta liberalización cultural y contaban una serie de candidatos al profesorado cuya formación y concepción de la filosofía del Derecho no se ajustaban al modelo que se consideró ortodoxo. Pero, como ya le he dicho, justamente por entonces ya habían salido del ámbito de la filosofía del Derecho algunos profesores que habrían podido contribuir de forma decisiva a ponerla en sintonía con los tiempos. En ese momento Elías de Tejada intervino haciendo uso de toda su combatividad y utilizando como criterio la adhesión al yusnaturalismo tal como él lo entendía. Sin embargo, tampoco usó este criterio de forma regular, con imparcialidad, pues en varias ocasiones opositores que sin duda eran yusnaturalistas fueron postergados en favor de otros por razones puramente subjetivas. Durante unos años su intervención produjo grave trastorno y desconcierto en la marcha de la disciplina, y perjuicios importantes a una serie de personas. Después se produjo un movimiento de oposición que frenó su influencia, y en el que jugaron un papel decisivo algunos profesores que a veces se incluyen indiscriminadamente en una pretendida "escuela" del Prof. Elías de Tejada. Es significativo en este sentido 
que, en el marco de las tensiones que se produjeron, con quien primero se enemistó abiertamente Elías de Tejada fué con Agustín de Asís, su primer y verdadero discípulo directo; le siguió en el turno Mariano Hurtado y, por último, Nicolás López Calera y yo con motivo de las oposiciones de 1974 a las que aludí antes cuando me referí a la intervención que en ellas tuvo el profesor González Vicén.

M.A.R.: Usted se educó como filósofo del Derecho en un clima fuertemente dominado por un yusnaturalismo de corte muy tradicional. En 1964 publicó en los Anales de la Cátedra Francisco Suárez un extenso artículo sobre "Derecho, Historia, Derecho Natural", que, si no me equivoco, se inscribía en un contexto de problemas suscitado por el fenómeno del renacimiento del yusnaturalismo tras la segunda guerra mundial. En su Lección Inaugural del curso 1982/83 vuelve usted sobre el tema, haciendo una especie de balance sobre la tradición del yusnaturalismo. ¿Cuál cree que es la contribución del yusnaturalismo a la filosofía del Derecho? ¿Cómo ve su propia relación con esa tradición?

J.D.P.: Efectivamente, como correspondía a la época, mi formación como filósofo del Derecho tuvo una clara orientación yusnaturalista. Supuso un conociminto bastante profundo de la tradición del Derecho natural, especialmente de la tradición premoderna, aunque a varios de los autores del yusnaturalismo racionalista los había leído antes. Posteriormente fuí sometiendo a revisión las convicciones de entonces, tomando en consideración las objeciones que implicaba la filosofía jurídica dominante en los siglos XIX y XX. Las publicaciones a que usted se refiere fueron, en buena medida, fruto de ese reexamen, aunque entre ellas hay claras diferencias. En la de 1964 indagaba cómo el Derecho natural, que concebía como distinguible del positivo, podía ser compatible con la historicidad del hombre y de la cultura. En la lección de 1982, aunque de forma muy sintética, se pone manifiesto una concepción diferente, conforme a la cual el mantenimiento de lo que hay de válido en la tradición yusnaturalista no requiere salvar el dualismo Derecho natural/Derecho positivo.

Del legado del yusnaturalismo creo que hay que destacar dos contribuciones de valor permanente. En primer lugar, el universalismo moral, enraizado en definitiva en su racionalismo. Es decir, la idea de que la rectitud o validez de los juicios morales no está subordinada a factores tales como la raza, las tradiciones culturales, etc.; y que, por tanto, con todas las condiciones y cautelas que se quiera, tiene sentido el intento de fundamentar principios morales universalmente válidos. En segundo lugar, la idea de una conexión necesaria entre Derecho y Moral, en el sentido de que la cuestión de la justicia no es sólo una cuestión externa al orden jurídico, sino también interna. Puesto que la pretensión de rectitud, de justicia, es inherente a las 
normas del Derecho, hay que entender la práctica jurídica, al menos en parte, como búsqueda de lo justo; eso sí, de acuerdo con las circunstancias y los condicionamientos institucionales pertinentes. Además de las anteriores, se pueden señalar también otras contribuciones del yusnaturalismo de carácter y valor históricos. Así, por ejemplo, la sistematización de la materia jurídica que se llevó a cabo en el proceso codificador y, en parte también, en la estructuración de la dogmática jurídica continental, se debe en buena medida a la labor del yusnaturalismo racionalista. Y nadie niega que la idea misma de derechos humanos se gestó también en la matriz yusnaturalista.

Ahora bien, el mantenimiento de lo que tiene valor permanente de la tradición yusnaturalista no requiere mantener también la terminología, ni la metodología, ni siquiera todos los presupuestos filosóficos del yusnaturalismo. En mi opinión se puede expresar utilizando el enfoque y los instrumentos de la filosofía contemporánea. Creo que es inutil intentar hacer valer hoy en sus propios términos teorías formuladas siglos atrás y que han quedado sobrepasadas por el proceso de discusión filosófica. Considero que en relación con ellas lo que se debe hacer es buena historiografía, que permita comprender el papel que desempeñaron en su momento y distinguir los elementos condicionados por el tiempo histórico de las ideas de valor permanente.

M.A.R.: ¿No cree usted que el hecho de que el régimen franquista hiciera del yusnaturalismo tradicional una doctrina oficial ha sido entre nosotros un obstáculo para una relación libre de prejuicios y de tensiones con la teoría del Derecho natural? Más aún, ¿no cree que ha impedido un trato sereno con nuestra propia tradición yusnaturalista, por lo demás tan brillante en los siglos XVI y XVII?

J.D.P.: Creo que, en efecto, así fue. Durante toda aquella época la polémica a propósito del yusnaturalismo estuvo viciada por prejuicios, por previas tomas de posición de carácter político. Si los partidarios del régimen profesaban el yusnaturalismo, era en buena medida porque formaba parte de una tradición con la que la ideología dominante afirmaba que se debía anudar. Y los que se oponían al regimen lo rechazaban por lo mismo: porque lo consideraban un elemento integrante la trama cultural con el que el regimen pretendía justificarse; y ello aunque en la mayor parte de los casos sus ideas sobre el Derecho no fueran claramente positivistas. Casi nunca se planteó la polémica en los términos adecuados, es decir, como una discusión sobre la capacidad explicativa de ambos enfoques, yusnaturalismo y positivismo jurídico; sobre cuál de ellos permite una comprensión más cabal del orden y la práctica jurídicos como parte del conjunto del orden social.

De todas maneras, aunque en España durante el régimen franquista la polémica sobre el yusnaturalismo sufriera esa especial deformación a la que 
ya he aludido, creo que tampoco fuera de nuestro pais se desarrolló casi nunca de modo ejemplar. En términos generales, durante el pasado siglo $\mathrm{XX}$ yusnaturalistas y positivistas se combatieron tomando cada bando como blanco de sus críticas, no la teoría del contrario fielmente reproducida, sino una caricatura o, al menos, una simplificación de la misma, de forma que, en cierto modo, se criticaban construcciones teóricas confeccionadas ad hoc para resaltar y definir mejor las tesis propias. Por poner algún ejemplo, baste recordar, del lado del positivismo, la imagen de la doctrina del Derecho natural que dibujaba Kelsen en su monografía de 1928, en la que contraponía los fundamentos filosóficos de ambas teorías: según él los defensores del yusnaturalismo concebían el Derecho como un "sistema normativo estático" en el que a partir de un primer principio, cuya justicia se estimaba evidente, se derivaban por pura deducción racional todos los restantes preceptos del sistema. O la simplificación en que incurría el propio Hart cuando afirmaba que el yusnaturalismo en general mantenía un concepto restrictivo de Derecho en cuanto que, según dicha doctrina, cualquier norma injusta dejaba de ser jurídica. En ambos casos se simplificaban doctrinas históricas mucho más sutiles. Pero del lado del yusnaturalismo también se pueden acumular los ejemplos: baste mencionar, como emblemático, la imagen que muchos yusnaturalistas presentaban del positivismo jurídico en general como una teoría cómplice de los regímenes tiránicos, en concreto como una teoría que en parte fue responsable de los horrores del nacionalsocialismo.

Volviendo a la España de la época franquista, dado como se planteó la polémica sobre el Derecho natural, es lógico que la consideración de la Escuela del Derecho Natural y de Gentes de los siglos XVI y XVII se encontrara en el centro de la misma. Unos la exaltaron retóricamente y le dedicaron numerosos estudios - entre los que hay de todo. Y otros la menospreciaron o, al menos, la ignoraron y orientaron los trabajos sobre la historia de nuestro pensamiento jurídico y político hacia otras épocas. Hace ya tiempo que se restableció el clima necesario para una valoración ecuánime de la obra realizada por aquel conjunto de teólogos y juristas. Y en ese clima la mayoría de los estudiosos reconoce la gran importancia de su aportación en el conjunto de la historia del pensamiento jurídico y político de Occidente.

Pero, como he dicho anteriormente, creo que ese reconocimiento no debe traducirse en un intento de trasplantar a nuestro tiempo construcciones teóricas que tuvieron sentido y cumplieron su papel en otra coyuntura histórica. Lo que hay que hacer es, ante todo, es poner de relieve, mediante los estudios pertinentes, ese sentido y ese papel histórico. Existen ya bastantes y bastante buenos trabajos de este tipo. Quizá se eche de menos uno de conjunto, a la par que bien documentado, que haga un balance de la signifi- 
cación histórica de la Escuela. Un estudio así tendría que tener en cuenta y valorar tanto el punto de vista de quienes la consideran negativamente por haberse apartado de la ortodoxia del sistema tomista, como hacen Michel Villey o John Finnis por citar algún nombre, como el de quienes la ignoran y consideran que la filosofía jurídica y política moderna arranca sin precedentes con Grocio o Hobbes. Además de lo anterior, también tiene sentido rescatar aquellas ideas o planteamientos cuyo valor transciende la coyuntura histórica para continuarlos, pero reelaborándolos en términos actuales. En esta línea me gustaría llamar la atención sobre la renovada importancia que cobra la elaboración de un Derecho de Gentes en la actualidad. En el siglo XVI los teólogos y juristas españoles respondieron a los desafíos que trajo consigo la apertura del horizonte histórico-geográfico sentando las bases del Derecho de Gentes. Hoy día, de nuevo, éste está llamado a constituir una parte sustancial de una teoría de la justicia a la altura de las circunstancias presentes, ya que la dimensión de los problemas más relevantes hace que cada vez resulte más insatisfactoria una teoría de la justicia que se circunscriba al ámbito de la comunidad política estatal.

M.A.R.: Uno de los focos más importantes de su trabajo lo constituye el desarrollo del positivismo jurídico en el siglo XX; en particular el pensamiento de Kelsen, Ross y Hart. Sus últimos cursos de Filosofía del Derecho en Salamanca se ocupan precisamente de ese desarrollo. ¿Cuáles cree usted que son las principales contribuciones de esa línea de pensamiento?

J.D.P.: Desde hace algún tiempo el curso que explico a los alumnos del último año de la Licenciatura versa, en efecto, sobre el desarrollo, las vicisitudes, y la crisis del positivismo jurídico en el siglo XX, y se centra, fundamentalmente, en una exposición comparativa del pensamiento de Kelsen, Ross y Hart. Pretende mostrar las posibilidades y los límites del positivismo jurídico. Creo que un estudio de este tipo es un buen modo de conseguir que los alumnos de quinto curso capten y reflexionen sobre las pretensiones y los problemas de la filosofía del Derecho.

El positivismo jurídico — que obviamente es una amplísima corriente, internamente diversificada - puede entenderse, al menos en parte, como la teorización de la práctica jurídico-política propia del Estado moderno, una vez que éste alcanza su consolidación. Cuando eso ocurre, se pone de manifiesto la creciente diferenciación que se ha ido produciendo entre los órdenes normativos sociales, y hasta qué punto el Derecho, como instrumento básico del poder del Estado, ha quedado desvinculado de otras normatividades como la religión, las tradiciones sociales y la moral. El positivismo jurídico es la teoría que pretende explicar el Derecho como un orden normativo autosuficiente, suceptible incluso de constituirse en objeto de un conocimiento científico propio, al margen de valoraciones morales, 
consideraciones de oportunidad política, etc. En el despliegue de ese intento los autores positivistas han llevado a cabo un análisis de la estructura interna y del funcionamiento del orden jurídico como no se había realizado en épocas anteriores. En eso radica su gran mérito y constituye una aportación irrenunciable y que debe ser continuada.

Ahora bien, a veces ocurre que la reflexión teórica sobre las prácticas sociales terminan presentándolas como si estuvieran dotadas de un grado de sistematicidad y autoconsistencia, de autofundamentación, mayor del que en realidad tienen. Esto, que suele darse también respecto de otros sectores de la vida social, creo que ha ocurrido a propósito del Derecho, de la práctica jurídica. Y en eso radica la limitación del positivismo jurídico en cuanto explicación filosófica del Derecho: en que al pretender presentar la práctica de los actores jurídicos y de los estudiosos del Derecho como si estuviera dotada de un sentido propio completamente independiente de consideraciones morales y políticas no permite una comprensión adecuada del fenómeno.

Aunque el positivismo es ya la teoría jurídica dominante en el siglo XIX, el curso que explico se refiere más bien a su desarrollo en el siglo XX. Lo hago así, primero por razón del tiempo disponible, pero, sobre todo, porque es en el siglo pasado cuando el positivismo jurídico alcanzó un mayor grado de articulación teórica. Como he dicho, centro la explicación en la obra de Kelsen, Ross y Hart porque, a mi juicio, representan las alternativas fundamentales que se han producido a lo largo del pasado siglo XX: no sólo las que mayor influencia han tenido, sino además las que presentan perfiles teóricos más definidos. Kelsen, que sustenta una concepción normativista, influída por el neokantismo, entiende el derecho como una construcción de la ciencia jurídica, que él quiere concebir como una ciencia normativa rigurosamente depurada de residuos sociológicos, morales e ideológicos. Ross defiende, en cambio, una concepción empirista, dentro de la cual el derecho se ve más bien como un fenómeno social que debe abordarse con las herramientas metodológicas de las ciencias empíricas. El caso de Hart es algo diferente, porque la adopción de un enfoque derivado de la filosofía del lenguaje le permite rescatar el carácter específicamente normativo del lenguaje y la práctica jurídica, sin dejar de contemplarlos como vinculados a prácticas sociales complejas.

Cada una de las tres doctrinas tiene sus puntos débiles y sus limitaciones. Un normativismo estricto, conducido con pureza metódica, llevaba a Kelsen formalizar la noción de deber, reduciéndolo a una pura forma mental que habría de permitir a los juristas conceptuar como jurídica cualquier relación política de dominio que fuera eficaz. El reduccionismo empirista impidió a Ross ofrecer una concepción aceptable sobre la normatividad del derecho y sobre los enunciados normativos, que son parte sustancial del lenguaje jurí- 
dico. El enfoque de Hart permite sortear esta dificultad: en la recuperación de un ámbito propio para la normatividad del Derecho frente al reduccionismo empirista se acerca a Kelsen; pero sin la rigidez de la de Kelsen, entre otras razones porque le es completamente ajeno el propósito kelseniano de fundamentar una pretendida ciencia jurídica rigurosa. Su forma de utilizar el análisis del lenguaje para afinar la comprensión de nuestras formas de vida, de nuestras prácticas sociales, le permite elaborar una teoría que rechaza reducir el Derecho a mera técnica de regulación del uso de la fuerza, pero se mantiene firme en la ortodoxia positivista al negar cualquier tipo de conexión necesaria con la moralidad.

El curso se ocupa detenidamente de esos tres autores, y trata de organizarlos de forma que salga a la luz la relación polémica en que se encuentran sus respectivos enfoques. Con ello intento de paso hacer un balance sobre el positivismo a finales del siglo XX. Pero, como ve, el estudio es fragmentario, y no se ocupa de forma independiente de algunos autores muy importantes: por ejemplo, de Bobbio. A Bobbio lo tengo en cuenta, y repetidamente aludo a sus puntos de vista y los comento. Si no lo hago objeto de una consideración aparte, es porque, a mi modo de ver, no expone una teoría jurídica sistemática basada en una opción filosófica diferente de las tres aludidas.

M.A.R.: Permitame que prolongue un poco más el tema. En la actualidad parece admitirse de forma general que el positivismo jurídico ha entrado en una seria crisis. ¿Cuáles cree usted que son los factores principales de esa crisis? Por lo demás, ¿cree que se trata aquí de un nuevo retorno del derecho natural, o más bien de que la vieja alternativa "o positivismo o yusnaturalismo" está empezando a ser inservible?

J.D.P.: Es verdad que últimamente el positivismo jurídico se encuentra en una situación de crisis, sometido a un proceso muy amplio de crítica, del que me parece que no podrá salir sin modificar algunas de las tesis básicas que lo definen como corriente filosófico-jurídica. A mi juicio la causa no se encuentra en las objeciones que períodicamente han venido formulando contra él los diversos rebrotes del yusnaturalismo, sino, ante todo, en un proceso de autocrítica, engrendrado en el interior del movimiento positivista, en el que varios de sus representantes más reconocidos han sometido a polémica las respectivas posiciones. Este primer factor se ha visto potenciado por las discusiones promovidas por un conjunto de teóricos que, sin ser yusnaturalistas, tampoco comparten plenamente el núcleo doctrinal del positivismo; pienso en autores como Lon Fuller, Robert Alexy, Carlos Nino y Ronald Dworkin entre otros.

Estas razones, relativas al desarrollo interno de la teoría del Derecho, han encontrado un apoyo decisivo en otras determinadas por ciertos rasgos 
del contexto jurídico-político imperante en los países occidentales en el último medio siglo. En las últimas décadas hemos asistido a la generalización de una forma de Estado en la que los textos constitucionales han positivizado el ideal ético-político de los derechos humanos a través de normas redactadas (muchas veces inevitablemente) de forma muy abstracta, suceptibles de interpretaciones diversas y conflictivas. Al mismo tiempo se ha institucionalizado también de forma general la protección jurisdiccional del orden constitucional, incluso frente a las variaciones legislativas. Todo esto ha dado lugar, entre otras cosas, a una práctica jurisdiccional que ha puesto al descubierto algo que en períodos anteriores quedaba más velado, a saber, el importante papel que en la argumentación de los actores jurídicos juegan los llamados principios del Derecho, muchos de los cuales poseen, claramente, naturaleza moral.

Un punto de inflexión decisivo en este proceso de crítica y autocrítica del positivismo jurídico lo marcó la obra de Hart. (Entre paréntesis me gustaría decir que me sorprendió la confesión que hizo en la primera página del Postscript que acompaña a la segunda edición de El concepto de Derecho, de que escribió el libro pensando en los estudiantes de Licenciatura; la sorpresa inicial se atempera luego, cuando uno cae en la cuenta de que se trata, en efecto, de un libro cuya densidad temática y las muchas novedades doctrinales que incorpora quedan en parte ocultas por un modo de exposición que hace muy fácil y agradable la lectura). Pero volvamos a lo que decía sobre el conjunto de su obra. Aunque nadie pone en duda que Hart fue hasta el final un firme defensor del positivismo, y en particular del que consideraba, con razón, su postulado central -la separación estricta entre Derecho y Moral-, lo cierto es que varias de las novedades teóricas que aportó dieron lugar a que comentaristas y críticos emprendieran polémicas en las que ese mismo postulado terminó poniéndose en cuestión. Vista retrospectivamente, e incurriendo en una cierta exageración, podría decirse que la obra de Hart ha sido para el positivismo jurídico una especie de caja de Pandora, pues ha abierto a los críticos algunos de los flancos más vulnerables del positivismo.

Para ser breve sólo recordaré alusivamente dos de esos frentes polémicos, por lo demás bien conocidos. En primer lugar, el suscitado por la insistencia de Hart en la prioridad del punto de vista interno para comprender como operan las normas en la práctica social. Esa insistencia estaba llena de buen sentido. Ahora bien, el punto de vista interno implica la aceptación de las normas; y eso, a su vez, supone entre otras cosas la disposición a justificar nuestra conducta apelando a las mismas. Esta doctrina de Hart dio lugar a que algunos pusieran de relieve que la pretensión de rectitud, de legitimidad, es algo inherente a las normas del Derecho, y a que destacaran el papel de las mismas como fundamento de juicios de deber que implican 
exigencias que han de primar sobre los intereses particulares. Todo ello hizo que terminara planteándose la pregunta de si estas características de la normatividad jurídica pueden explicarse desde una concepción del Derecho positivo como un orden autosuficiente, cerrado en sí mismo, o requieren más bien una concepción diferente que admita su conexión con la moral.

El segundo de los frentes polémicos abiertos por Hart tiene que ver con su inequívoca aceptación del carácter incompleto del sistema jurídico, de la existencia de lagunas, y su doctrina de que en tales supuestos el juez debe actuar discrecionalmente echando mano de pautas extrajurídicas. Ahora bien, una vez que se admite que las leyes no dan todas las respuestas que necesitan los jueces en su práctica normal, es inevitable preguntarse por qué han de considerarse como extrajurídicas las pautas a las que recurren en ausencia de ley claramente aplicable, y por qué no más bien como parte del Derecho vigente. Eso induciria a abandonar el concepto del mismo como un sistema bien definido de reglas, que resulta ser un concepto estrecho, inadecuado. Como es sabido, éste es el frente por el que se orientó inicialmente el ataque de Dworkin, al poner de relieve el papel de los principios morales en la práctica jurisdiccional.

En suma, anudando con lo que dije al principio, el hecho es que por las causas apuntadas, y tal vez también por otras que en este momento se me escapan, en los últimos quince o veinte años se ha venido desarrollando un diálogo polémico de teóricos positivistas entre sí, y con otros que no se consideran rigurosamente tales, en el que las tesis distintivas del positivismo jurídico se han ido analizando, refinando, y finalmente minimizando. En esta tesitura algunos autores defienden un positivismo "incluyente" o "flexible", que otros critican; mientras que varios sostienen teorías claramente postpositivistas. Es difícil saber como terminará este proceso crítico. De todas maneras, respondiendo a la última parte de su pregunta, lo que sí me parece seguro es que no se producirá una vuelta al yusnaturalismo. El yusnaturalismo nunca ha sido una verdadera alternativa al positivismo jurídico, pues la historia no transcurre en vano. El yusnaturalismo constituyó una modalidad de filosofía del Derecho adecuada a unas circunstancias históricas que desaparecieron hace siglos, y que no se van a repetir. Si hubiera que arriesgar un pronóstico, supongo que antes o después se elaborará una teoría que, sin ser fruto de un mero sincretismo, supondrá una correción del positivismo jurídico capaz de recoger las aportaciones de valor permanente de la tradición yusnaturalista.

M.A.R.: A lo largo de estos cuarenta años mucho ha cambiado entre nosotros. ¿Cuáles son en su opinión los cambios más importantes que se han producido en la filosofia del Derecho? 
J.D.P.: Puestos a hablar de cambios, hay uno de gran magnitud que me parece que no debería dejar de mencionar. Me refiero al número de profesores de filosofía del Derecho. Hasta la primera mitad de los años setenta, aproximadamente, éramos unos quince catedráticos y, quizá, el doble entre profesores adjuntos y los primeros profesores agregados. Nos conocíamos todos. Si uno no se desentendía, podía estar perfectamente al tanto de la trayectoria de los demás; y las nuevas publicaciones podían ser conocidas casi de inmediato. Hoy entre catedráticos y profesores titulares debemos sumar varios cientos, con lo que ni nos conocemos todos personalmente, ni es posible tener noticia, sin notable retraso en muchas ocasiones, de cuanto se hace y se publica.

Respecto de las direcciones de pensamiento, la división y oposición entre yusnaturalistas y positivistas (o tal vez mejor, antiyusnaturalistas), de los años sesenta se fué diluyendo en las décadas posteriores hasta casi desaparecer. Si hubiera que hacer un recuento, creo que ahora son más los que siguen considerándose positivistas y escriben defendiendo esa corriente de pensamiento, que los defensores del yusnaturalismo, al menos de la concepción tradicional del mismo. Podría hablarse de un debilitamiento de esa corriente doctrinal. Pero a mí me parece que es mucho mayor el número de aquéllos que no se sitúan, inicialmente y sin distinciones, en una u otra posición.

Probablemente el cambio más llamativo en la orientación del pensamiento entre nosotros ha sido el imparable ascenso del enfoque analítico. Más o menos a comienzos de los setenta penetró en nuestro país la confrontación que se había dado en Alemania entre "analíticos" y "dialécticos". Aunque esa polémica se manifestó principalmente en otras disciplinas cercanas, también tuvo su repercusión en la filosofía del Derecho. Inicialmente y durante un tiempo tal vez fueran más y más notorios los autores que podían incluirse en la orientación dialéctica, tomada en sentido amplio, que abarcaría desde quienes intentaron reconstruir una teoría marxista del Derecho y del Estado, a aquellos que únicamente adoptaron algunas ideas o enfoques de inspiración marxista, o los que propugnaron en España el "uso alternativo del Derecho". Sin embargo, la evolución posterior ha traído consigo la difusión y el dominio casi indiscutido del enfoque analítico. Esta evolución se corresponde con la que ha tenido lugar en otros paises. Y es que, por lo que se refiere a las corrientes de pensamiento dominantes, la filosofía jurídica española ha dejado de ser un caso aparte para equipararse con la que se cultiva fuera de nuestras fronteras.

También en cuanto a los temas estudiados se han producido cambios significativos a lo largo de estos cuarenta años. En algunos de los temas que han sido objeto de atención y de estudio en todas las etapas se han registrado cambios sustanciales en cuanto al enfoque y en cuanto a la doctrina 
defendida. Otros temas que habían sido poco estudiados en etapa anteriores, más o menos durante el regimen franquista, han experimentado un notable desarrollo en las últimas décadas. Permítame una alusión a esos cambios, organizándola esquemáticamente en los tres grandes bloques temáticos convencionales: teoría de la justicia, teoría del derecho, y metodología y teoría de la argumentación.

Uno primero es el correspondiente a la teoría de la justicia y, como parte de ella, a la doctrina sobre los derechos humanos. En realidad esa temática nunca dejó de ser objeto de estudio, y sobre ella se publicaron trabajos más o menos importantes en todos los momentos a lo largo de estos cuarenta años. Pero la orientación de la doctrina experimentó un cambio completo. En los años cuarenta, cincuenta y todavía durante los sesenta los estudios sobre la justicia adoptaron de forma casi unánime el enfoque propio del yusnaturalismo neoescolástico; $\mathrm{y}$, de forma coherente, se desarrolló un doctrina sobre los "derechos naturales" de orientación premoderna y restrictiva. Sin embargo, desde finales de los sesenta fue imponiéndose progresivamente un enfoque más acorde con los tiempos, integrando las investigaciones sobre los derechos humanos y los derechos fundamentales en el marco más amplio de una filosofía política democrática. Me gustaría añadir, a modo de apostilla, que los muchos y buenos estudios que se han producido entre nosotros sobre derechos humanos han mostrado un cierto desconcierto a propósito de la cuestión, típicamente filosófico-jurídica, de la fundamentación de los mismos, cuya causa creo que no es difícil identificar. Parece claro que el fundamento de los derechos debe encontrarse en ciertas normas que pretenden ser objetivamente válidas, más precisamente, en ciertos principios de justicia relativos a la organización básica de la comunidad política. La formulación y justificación de tales principios es tarea propia de una teoría de la justicia. Ahora bien, excluídas las teorías sobre la justicia de inspiración yusnaturalista, no se disponía de otras doctrinas suficientemente articuladas, en las que apoyarse. La renovación radical de la teoría de la justicia se ha producido gracias a la obra de J. Rawls. Pero, aunque su pensamiento ha tenido una importante difusión entre nosostros, y ha sido objeto de comentarios y discusiones, creo que no ha sido todavía suficientemente explotado como punto de partida para una teoría de los derechos humanos. En todo caso, creo que el lugar de la teoría de los derechos humanos en una teorìa de la justicia sigue siendo impreciso entre nosotros.

Un conjunto de temas que no recibió demasiada atención hasta no hace muchos años es el de aquellos que suelen incluirse en una teoría del derecho en sentido estricto: la teoría de la norma jurídica, el análisis de los distintos tipos de normas, la naturaleza y estructura del sistema jurídico y los distintos problemas implicados en ella, etc. Hasta cierto punto es explicable que 
se prestara poca atención a estos temas, que constituían la temática más específica de la teorías positivistas. No es que no se escribiera nada sobre ellos. Algo se hizo. Pero fundamentalmente fueron los civilistas los que se ocuparon de algunos de dichos temas. Después, sin embargo, la teoría del derecho ha experimentado un amplísimo desarrollo entre nosotros, y se han producido muchas aportaciones, algunas de extraordinario valor.

Algo parecido creo que puede decirse a propósito del bloque temático que comprende las cuestiones relativas a la metodología y la argumentación jurídica en general. En un primer período encontramos pocos estudios sobre estas cuestiones, aunque no puede ignorarse algún trabajo innovador, como el de Recaséns en los años cincuenta sobre la interpretación. En las últimas décadas, por el contrario, abundan las investigaciones centradas en esta temática, y varias de ellas son muy valiosas.

M.A.R.: A veces tendemos a pensar que el pensamiento filosófico avanza obedeciendo a impulsos endógenos. Y seguramente en parte eso es verdad. Pero es indudable que la historia social y política tiene una influencia decisiva en la marcha del pensamiento. ¿Cómo cree usted que el final del franquismo y la instauración de un Estado constitucional democrático ha afectado a la filosofía del Derecho en nuestro pais?

J.D.P.: Yo creo que el pensamiento filosófico avanza y evoluciona como consecuencia de la influencia combinada de ambos factores: la propia dinámica interna del pensamiento filosófico y, no lo olvidemos, del científico; y, por otro lado, las transformaciones en la estructura social y la organización política. Sólo de tarde en tarde, por obra de algún pensador excepcional o debido a un cambio político social profundo y brusco - pienso, por ejemplo, en la revolución francesa-, uno solo de ambos factores determina un viraje en la marcha de la filosfía.

En mi opinión el final del franquismo no trajo consigo novedades radicales en la marcha de la filosofía del Derecho. Como en otras facetas de nuestra vida social y cultural, lo que hizo fué potenciar y acelerar el desarrollo de tendencias que ya existían, y que contribuyeron a que la filosofía jurídica española acabara equiparándose a la que se cultivaba en otros paises.

Algo parecido pude decirse respecto de la influencia ejercida por la instauración y la experiencia del funcionamiento del Estado constitucional democrático. Por un lado, potenció el desarrollo de la nueva orientación que ya se venía imponiendo desde algunos años atrás en las investigaciones sobre derechos humanos y derechos fundamentales. Por otro, ha dado lugar a una jurisprudencia en la que juegan un importante papel explícito los principios y valores fundamentales, y eso ha impulsado a la doctrina a discutir algunas de las tesis propias de un positivismo jurídico estricto, cosa que ya venía ocurriendo en otros paises como Italia y Alemania. 
M.A.R.: Recuerdo muy bien uno de los consejos que usted me dio en una de las primeras conversaciones que tuvimos, cuando yo empezaba a estudiar filosofía del Derecho: "estudie alemán". Y en ese momento ese era un consejo muy sensato. Hoy, sin embargo, parece que más bien hay que aconsejar estudiar inglés, porque el peso de la filosofía del Derecho escrita en inglés es abrumador; incluso la filosofía del Derecho alemana ha terminado siendo en cierta medida tributaria de la angloamericana. ¿Pero no cree que en la actualidad la filosofía del Derecho escrita en español se mueve en un nivel que resiste la comparación con la que se realiza en otros paises? ¿Cómo ve el presente de la filosofía del Derecho española?

J.D.P.: Me imagino que que ese consejo iría acompañado de otro que le emplazaría a "estudiar a los clásicos". Lo digo porque se trata de dos recomendaciones que era costumbre formular a quienes decidían dedicarse a la filosofía del Derecho. Aunque los tiempos han cambiado, creo que siguen siendo consejos válidos.

Pero es verdad que precisamente por el cambio de los tiempos hoy el consejo tendría que ser, ante todo, el de que hay que dominar el inglés. Porque la primacía de la filosofía jurídica anglosajona es innegable. Pero no sólo en el campo de la filosofía del Derecho, sino también en el de la filosofía moral y la filosofía política. Y no podría ser de otro modo; pues no parece posible un desarrollo floreciente y duradero de la filosofía jurídica sino como consecuencia de los estímulos recíprocos entre las distintas parcelas de la filosofía práctica y, en suma, de la filosofía en general. No se trata ahora de indagar las causas de esa primacía, sino simplemente de constatar el hecho y de atenerse a él.

En cuanto a la filosofía del Derecho alemana, ciertamente, desde hace unas décadas se encuentra en un proceso de cierto decaimiento. Lo reconocen los propios filósofos del Derecho alemanes. Sería interesante extenderse sobre las razones que pueden explicar ese proceso, pero no parece el momento oportuno. Decir que la actual filosofía jurídica alemana es tributaria de la anglosajona creo que sólo es verdad a medias. Lo que sí es cierto es que en este momento no se entiende la obra de los autores alemanes más relevantes, sino poniéndola en relación con la de determinados autores ingleses y norteamericanos e, incluso, de otros países; es decir, viéndola como fruto de un debate que traspasa las fronteras. Porque un hecho importante que marca la especulación filosófica desde hace unas décadas es que han caído las barreras que mantenían relativamente incomunicadas las diversas "tradiciones" filosóficas nacionales. Lo que caracteriza a nuestro momento histórico es que se ha producido la universalización inmediata del debate filosófico. Y eso es algo que me parece sensato y positivo. Si el saber científico es uno, universal, y no tendría sentido el mantenimiento de tradiciones científicas nacionales 
relativamente independientes, creo que análogamente la reflexión filosófica debe desenvolverse en un ámbito de comunicación universal. Lo que no será obstáculo para que cada ámbito lingüístico mantenga un estilo propio y se constituya en el terreno más inmediato de intercambio y de debate.

En este contexto es en el que hay que situar y valorar la actual filosofía del Derecho española. Yo creo que, en efecto, resiste perfectamente la comparación con la de otros países. Los temas que se tratan son fundamentalmente los mismos que se debaten en otras partes, y el número y la calidad de las publicaciones no es menor que el de cualquier otro país. Si nos fijamos únicamente en las contribuciones de más alto valor, aquéllas que van abriendo el camino en las distintas materias sometidas a discusión, también hay que contar entre ellas varias escritas en español. Digo escritas en español, acogiéndome al tenor literal de su pregunta, lo que nos permite tener en cuenta los trabajos de nuestros colegas iberoamericanos. Varios trabajos de unos cuantos de estos colegas, algunos fallecidos no hace mucho, y otros tantos de autores españoles poseen la calidad suficiente para situarse en esa vanguardia del debate filosófico-jurídico internacional. Y si algunos no han obtenido aún la difusión merecida, se debe a la persistencia de las barreras idiomáticas. Claro que se trata de los trabajos de una escasa minoría, si tenemos en cuenta la totalidad de los dedicados al cultivo de la filosofía del Derecho. Pero esa proporción es parecida a la que se da en cualquier otro ámbito lingüístico.

En resumen, creo que el presente de nuestra filosofía del Derecho es muy bueno, y que habría que pensar en qué medidas tomar para que mejore, o al menos no decaiga, en el futuro. Entre ellas hay una que me viene a la mente, sugerida por lo que he dicho hace un momento: que se debe mantener e intensificar el contacto permanente con nuestros colegas iberoamericanos.

M.A.R.: Tras cuarenta largos años profesando la filosofia del Derecho, ¿que consejos daría a los más jóvenes, a los que están iniciándose?

J.D.P.: Supongo que se refiere a aquéllos que aspiran a algo más que a ser profesores de filosofía del Derecho: que aspiran más bien a dominar la disciplina en su estado presente; no digo a hacerla avanzar, pues si lo anterior es ya muy difícil, esto último está reservado a unos pocos.

La verdad es que resulta difícil dar consejos útiles. Los que se me ocurren se traducen en orientaciones que no parece fácil compatibilizar. Recordando lo que he dicho antes, me parece evidente que es necesario dominar varios idiomas, pues hay que estar al corriente de lo que se publica en diversos países sin tener que depender necesariamente de las traducciones que, como desgraciadamente hemos podido comprobar últimamente, pueden llegar a ser muy deficientes. Sin embargo, también creo que hay que prestar más atención a las publicaciones en español, pues ahí esta nuestro ámbito inmediato de desarrollo y de debate. 
Es aconsejable estudiar a los clásicos, pues los más importantes problemas filosóficos y, por tanto, filosófico-jurídicos, persisten a traves de las épocas, y ellos los trataron con insólita profundidad y, en bastantes ocasiones, también con sencillez. Pero, por otro lado, es preciso "estar al dia" permanentemente; no puede uno vivir de las rentas e ignorar los avances de los últimos años. Ahora bien, ¿se pueden conseguir ambas cosas, dado el enorme volumen de lo que se publica últimamente? Parece muy difícil. Por eso es inevitable una selección drástica de la literatura que se produce a diario; y para ello tal vez sea conveniente el trabajo en equipo - algo para lo que en general creo que no estamos preparados. Una regla que puede ser útil es la de que a los autores importantes hay que leerlos directamente y no a través de exposiciones y comentarios de segunda mano; lo que no impide que en ocasiones un comentario pueda ser muy iluminador.

Estoy convencido de que no se puede hacer buena filosofía del Derecho sin estar al corriente de la situación en que se encuentran otras ramas de la filosofía, en especial la filosofía moral y la filosofía política, cuyos problemas se entrelazan con los de nuestra disciplina. La orientación de algunas cuestiones filosófico-jurídicas importantes depende de la posición que se adopte a propósito de problemas filosófico-morales como, por ejemplo, el relativo a la validez, o no validez, objetiva de los juicios morales. Por eso creo que tenía mucho sentido la existencia de un área de conocimiento que abarcara la filosofía jurídica, la moral y la política. Ahora bien, estar al corriente de la situación en esas otras parcelas de la filosofía requiere tiempo. ¿Es compatible con el dominio de la literatura más estrictamente filosófico-jurídica? En cualquier caso constituye una empresa verdaderamente muy difícil.

Se me ocurre una última recomendación que hacer a quien se inicia en nuestra disciplina, que es coherente con lo que he dicho antes y de la que hemos hablado en otras ocasiones. Se podría formular del siguiente modo: que, en la medida en que se lo permita el sistema de promoción del profesorado, no publique demasiado.

M.A.R.: Prof. Delgado Pinto, felicidades por su próxima jubilación, y muchísimas gracias por sus palabras.

\section{DOXA 25 (2002)}

